\title{
Economic cost of hospitalized non-fatal paediatric dengue at the Lady Ridgeway Hospital for Children in Sri Lanka
}

\author{
Manouri P Senanayake $^{1}$, Sankha SK Jayasinghe ${ }^{2}$, Dishni S Wijesundera ${ }^{2}$, Mihira Manamperi ${ }^{3}$
}

Sri Lanka Journal of Child Health, 2014; 43(4): 205-207

\begin{abstract}
Introduction: This is the first cost-of-illness study on dengue in Sri Lanka and compares economic costs incurred by hospital and households in Colombo during hospital stay of paediatric patients.
\end{abstract}

Method: A prospective cross-sectional study was carried out on cost of treating dengue at Lady Ridgeway Children's Hospital Colombo over six months (2012-2013) on randomly selected patients fulfilling diagnostic criteria of dengue. Parent interviews and medical records were used to assess costs incurred by households and hospital.

Results: Sample consisted of 130 non-fatal dengue patients [43 dengue haemorrhagic fever (DHF), 87 dengue fever (DF)]. None needed intensive care. Average hospital stay of DHF and DF patients was 4.8 and 3.8 days respectively. Average cost to hospital per case of DHF and DF was SLR 24,856 (USD 191) and SLR 10,348 (USD 80) respectively. Direct and indirect medical and non-medical costs incurred by households were SLR 4,758 (USD 36.6) for DHF and SLR 3,965 (USD 30.5) for DF. Total cost per illness for an episode of DHF was SLR 29,744 (USD 228.8). Cost per episode of DF was SLR 14,326 (USD 110.2). Government incurred $84 \%$ and $72 \%$ of the total costs of DHF and DF.

Conclusions: Publicly funded health care bears much of the economic burden of dengue illness in Sri Lanka. Weighted average cost of treating paediatric dengue in ward settings was SLR 19,422 (USD 149.4), representing 5\% of per capita GDP (USD 2923 in 2012). Although funding found by households was only $16 \%$ and $28 \%$ of total costs of DHF and $\mathrm{DF}$, in those below the 'poverty line', this amounted to $93.7 \%$ of monthly per capita income.

(Key words: Dengue; economic cost; Sri Lanka; paediatric dengue)

\section{Introduction}

Dengue is endemic in Sri Lanka. Children form a large part

${ }^{1}$ Senior Professor \& Head, ${ }^{2}$ Research Assistant,
Department of Paediatrics, Faculty of Medicine, Colombo,
${ }^{3}$ Registrar, University Unit, Lady Ridgeway Children's
Hospital Colombo

(Received on 18 February 2014: Accepted after revision on 14 March 2014) of the caseload with high hospital admission rates due to fear of severe complications ${ }^{1,2}$. This is the first study on economic cost of treating dengue in Sri Lanka and compares costs from hospital and household perspectives at the country's largest public-sector children's hospital in Colombo. In 2012, one fourth of the reported total annual dengue caseload was from the district of Colombo ${ }^{3}$.

\section{Method}

This prospective cross-sectional study describes cost and sources of funding of treating dengue in two wards of Lady Ridgeway Hospital for Children (LRH) Colombo, Sri Lanka. Parent interviews, medical records and available data on unit costs for different components of indoor patient care were used after obtaining permission from hospital authorities. Only consenting parents were included. Costs incurred by hospital and households during hospital stay were compared.

Children aged 0-12 years who fulfilled WHO clinical case definitions of a) Dengue haemorrhagic fever (DHF) b) Expanded dengue syndrome c) classical dengue fever (DF) with thrombocytopenia $\left(<100 \times 10^{9} / 1\right)$ and positive Hess test or had serological or virological confirmation formed the study population. The project was carried out in two of the six medical wards of LRH and every third patient who fulfilled the diagnostic criteria was enrolled irrespective of clinical severity. Study period of six months (1 December 2012 to 31 May 2013) included three months with high seasonal disease burden and three months with low incidence of dengue. Each patient's cost to hospital and household was calculated separately.

Individual patient's medical and nursing records were analysed for itemized cost to hospital with regard to length of hospital stay, cost of 'bed and services' provided, cost of laboratory investigations and medications administered. Cost of each item was calculated using costing data available with the hospital administration. Cost of human resource was included in "services".

An interviewer administered questionnaire, used during and at the end of hospital stay, gathered information from parents on socio-economic status, health seeking pathways and details of all illness-related expenses prior to and during hospitalization. Direct medical costs (medicines, investigations), direct non-medical costs (food, transportation, accommodation in Colombo) and indirect 
costs (loss of parental wages, cost of care givers) comprised the total expenses incurred at household level. Data was disaggregated to DHF and DF.

\section{Results}

During the study period, 507 patients were admitted with suspicion of dengue to two selected paediatric wards and 130 (43 with DHF and 87 with DF) who fulfilled the inclusion criteria were enrolled. Severity of DHF was: Grades 1 \& 2 (34), Grades 3 \& 4 (09). Serologic confirmation was available in only $48 \%$. Remainder fulfilled the clinical diagnostic criteria. Neither ward experienced fatalities, nor were any patients transferred for specialized intensive care for dengue. Average ward stay was 4.8 (SD 1.51) and 3.8 (SD 1.26) days for DHF and DF respectively. Circulating dengue serotype in Sri Lanka during the study period was almost entirely (99\%) Den 1. Disease severity showed plasma leakage (43) circulatory compromise (09), liver failure (05) and bleeding (02).
Full range of socio-economic strata was present in the study sample as determined by maximum level of education in household, and 95\% stated monthly per capita household income as over SLR 650 (USD 50). Three households $(02 \%)$ were below the 'poverty line' stipulated by Department of Census and Statistics, Sri Lanka for Colombo in $2013^{4}$.

Cost is presented as Sri Lankan rupees (SLR) and US dollars (USD) at a conversion rate of SLR 130 per USD, being the average for this time period. Average cost to hospital per day per patient with DHF was SLR 5,174, SD 1599 (USD 39.8, SD 12.3) and with DF was SLR 2717, SD 897 (USD 20.9, SD 6.9). Average cost to hospital per entire episode of DHF and DF was SLR 24, 856, SD 7670 (USD 191.2, SD 59) and SLR 10,361, SD 3380 (USD 79.7, SD 26.07) respectively. 'Bed and services' costs made up $85.3 \%$ and $79.1 \%$ of the total costs of DHF and DF to hospital; and investigations came next [Table 1]. Medications and infusions contributed very little (DHF $1.5 \%$ and DF $0.5 \%$ ) to total cost.

Table 1: Cost to hospital \& households during treatment for dengue at LRH (1 Dec 2012 - 31 May 2013)

\begin{tabular}{|c|c|c|}
\hline & $\begin{array}{c}\text { Dengue fever } \\
\mathbf{n}=\mathbf{8 7} \\
\text { SL Rupees (US Dollars) } \\
\end{array}$ & $\begin{array}{c}\text { Dengue haemorrhagic fever } \\
n=43 \\
\text { SL Rupees (US Dollars) }\end{array}$ \\
\hline $\begin{array}{l}\quad \text { Cost to hospital } \\
\text { Average cost per case per day } \\
\text { Average cost per illness episode } \\
\text { Bed and services costs } \\
\text { Investigation costs } \\
\text { Medications \& Infusion costs }\end{array}$ & $\begin{array}{c}2717(20.9) \\
10,348(79.6) \\
8190(63.0) \\
20,70(15.93) \\
52(0.4)\end{array}$ & $\begin{array}{c}5174(39.8) \\
24856(191.2) \\
21,229(163.3) \\
3198(24.6) \\
376(2.9)\end{array}$ \\
\hline $\begin{array}{l}\text { Cost to households } \\
\text { Average cost per illness episode } \\
\text { Average out-of-pocket expenditure per case } \\
\text { Direct medical costs (medicines \& investigations) } \\
\text { Direct non-medical costs (food, transport, lodging) } \\
\text { Indirect costs }\end{array}$ & $\begin{array}{c}3965(30.5) \\
3484(26.8) \\
1118(8.6) \\
2327(17.9) \\
500(3.9)\end{array}$ & $\begin{array}{c}4758(36.6) \\
3965(30.5) \\
1121(8.6) \\
2834(21.8) \\
798(6.1)\end{array}$ \\
\hline
\end{tabular}

Health seeking behaviour in 77\% included treatment from a local clinic or family physician prior to admission; resulting in a similar direct medical cost of SLR 1118 (USD 8.6) in both DHF and DF. During hospital stay the non-medical costs were for transport and food for parents, which totaled to, on average SLR 2834, SD 2340 (USD 21.8, SD 18.1) in DHF and SLR 2327, SD 1950 (USD 17.9, SD 15.0) in DF. Breakdown by type of cost is shown in Table 1. Loss of wages was not a major contributor because the patients were children and most parents were entitled to paid leave. Fathers lost only 2-2.5 days' work. Although mothers spent long hours at the child's bedside only a minority $(14 \%)$ experienced loss of wages. During hospital stay total out-ofpocket expenses per household per illness was on average SLR 3965, SD 2652 (USD 30.5, SD 20.4) and SLR 3484, SD 2210 (USD 26.8, SD17.0) for DHF and DF and total financial burden to households averaged SLR 4758 (USD 36.6) (DHF) and SLR 3956 (USD 30.5) (DF) per case in hospital. Total cost-of-illness (to both hospital and household) in DHF and DF was SLR 29,744 (USD 228.8) and SLR 14,326 (USD 110.2) per episode of illness, not needing admission to intensive care units.

\section{Discussion}

This study was prospectively designed to analyse cost of treating paediatric dengue patients in medical wards as well as the costs incurred by households during hospital stay. A public-sector hospital with a wide catchment area and a large caseload was the study setting. This hospital provides free health care irrespective of socio-economic status. Caseload is mostly from low or middle income families. Management of dengue is based on National Guidelines. Therefore two of six wards were considered adequately representative. The selection of the two wards was also based on logistical features of access and closer proximity. 
Every third patient was enrolled to avoid overloading investigator capacity. Medical staff of one of the selected wards were not involved in the research project, to eliminate bias and to make data collection that much more reliable. A limitation in this study was that none of the patients in this sample needed intensive care. Obviously, patients needing intensive care would increase hospital costs. Absence of fatalities reflects low case fatality in the country. Sample studied had patients with serious complications and there was no under enrolment of severe illness.

Cost of DF to the hospital was similar to that caused by any other acute childhood illness [estimated at SLR 860 (USD 22.0)]. However, DHF more than doubled costs even when intensive care unit (ICU) was not the treatment setting. Rise in cost of DHF was mostly due to 'services' i.e. for close monitoring and nursing rather than pharmaceuticals. Despite absence of hospital bills, households sustained a financial loss that averaged SLR 4758 (USD 36.6) (DHF) and SLR 3965 USD 30.5 (DF) per illness episode. Loss of wages was a minor contributor because illness was in children. Additional non-medical costs were incurred after leaving hospital by almost $77 \%$ households. These were for cultural and spiritual activities that stemmed from fear of the illness. We did not measure these indirect costs as they took place several weeks after leaving hospital. The overall cost of hospital treatment per case of DHF was SLR 29,744 (USD 228.8), which is $7.8 \%$ of the per capita GDP for Sri Lanka in 2012. Total cost per case in DF, SLR 14,326 (USD 110.2 ) represented $3.8 \%$ of per capita GDP. We found that government incurred $84 \%$ and $72 \%$ of the total costs in DHF and DF with households bearing only $16 \%$ and $28 \%$ of costs of DHF and DF respectively. If our findings on costing were to be extrapolated to annual aggregate national hospitalized paediatric dengue caseload the cumulative expenditure on the curative health sector in Sri Lanka would be a staggering sum, even without ICU costs, but lack of age-specific data prevented us from assessing the aggregate cost of paediatric dengue in hospitals in Sri Lanka.

\section{Conclusions}

The weighted average cost of treating paediatric dengue in Colombo (without availing of intensive care facilities) was SLR 19,422 (USD 149.4) per case. Weighted average cost to households was SLR 3964 (USD 32.8) which was 13.5\% of monthly per capita income. Due to the inequality of incomes we also considered the 'poverty line' stipulated by the Department of Census and Statistics in analyzing costof-illness ${ }^{4}$. Although only a small minority of households (2\%) was below the 'poverty line' these households spent $93.7 \%$ of their monthly per capita income per dengue illness in hospital. In some Asian countries households face greater burdens due to dengue ${ }^{5-9}$. In Sri Lanka publicly funded health care bears much of the cost of dengue.

\section{Acknowledgements}

We thank Dr. Samantha Waidyanatha Consultant Paediatrician LRH for permission to include patients in her ward, Prof Amala de Silva Dept. of Economics, University of Colombo for her invaluable guidance, Dr. L Kenderagama Senior House Officer for her assistance and Dr. Rathnasiri Hewage, Acting Director, LRH for permission to carry out this study.

\section{References}

1. Gubler DJ. Epidemic dengue/dengue hemorrhagic fever as a public health, social and economic problem in the $21 \mathrm{st}$ century. Trends in Microbiology 2002; 10:100-3. http://dx.doi.org/10.1016/S0966-842X(01)02288-0

2. Guzman A, Isturiz RE. Update on the global spread of dengue. International Journal of Antimicrobial Agents 2010; 36:540-2.

http://dx.doi.org/10.1016/j.ijantimicag.2010.06.018

3. Epidemiology unit, Ministry of Health Sri Lanka, Disease surveillance 2012/2013.

http://www.epid.gov.lk/web/index.php?option=com_cases anddeaths\&Itemid $=448 \&$ lang $=$ en

4. Department of Census and Statistics Sri Lanka 2013 www.statistics.gov.lk/poverty/monthly poverty/index.htm

5. Beatty ME, Beutels P, Meltzer MI, Shepard DS, et al. Health economics of dengue: a systematic literature review and expert panel's assessment. American Journal of Tropical Medicine and Hygiene 2011; 84:473-88. http://dx.doi.org/10.4269/ajtmh.2011.10-0521

6. Suaya JA, Shepard DS, Siqueira JB et al. Cost of dengue in eight countries in the Americas and Asia: a prospective study. American Journal of Tropical Medicine and Hygiene 2009; 80: 846-55.

7. Shepard DS, Coudeville L, Halasa YA et al. Economic impact of dengue illness in the Americas. American Journal of Tropical Medicine and Hygiene 2011; 84:2007.

http://dx.doi.org/10.4269/ajtmh.2011.10-0503

8. Beauté J, Vong S. Cost and disease burden of dengue in Cambodia. BMC Public Health 2010; 10:521. http://dx.doi.org/10.1186/1471-2458-10-521

9. Huy R, Wichmann O, Beatty M et al. Cost of dengue and other febrile illnesses to households in rural Cambodia: a prospective community-based case-control study. BMC Public Health 2009; 9:155.

http://dx.doi.org/10.1186/1471-2458-9-155 